\title{
Alpha Fetoprotein Adenoviral Vector Vaccine
}

National Cancer Institute

\section{Source}

National Cancer Institute. Alpha Fetoprotein Adenoviral Vector Vaccine. NCI Thesaurus.

Code C48372.

A vaccine consisting of a recombinant adenoviral vector encoding alpha fetoprotein. After vaccination, expressed alpha fetoprotein may stimulate a cytotoxic $T$ lymphocyte $(C T L)$ response against tumor cells that express alpha fetoprotein, resulting in tumor cell lysis. $(\mathrm{NCl} 05)$ 